\title{
Two years' experience of implementing a comprehensive telemedical stroke network comprising in mainly rural region: the Transregional Network for Stroke Intervention with Telemedicine (TRANSIT-Stroke)
}

Katharina M. A. Gabriel ${ }^{1 *}$, Steffi Jírů-Hillmann¹, Peter Kraft², Udo Selig ${ }^{1}$, Viktoria Rücker ${ }^{1}$, Johannes Mühler ${ }^{3}$, Klaus Dötter ${ }^{3}$, Matthias Keidel ${ }^{4}$, Hassan Soda ${ }^{4}$, Alexandra Rascher ${ }^{4}$, Rolf Schneider ${ }^{5}$, Mathias Pfau ${ }^{6}$, Roy Hoffmann ${ }^{7}$, Joachim Stenzel ${ }^{8}$, Mohamed Benghebrid ${ }^{9}$, Tobias Goebel ${ }^{10}$, Sebastian Doerck ${ }^{11}$, Daniela Kramer ${ }^{11}$, Karl Georg Haeusler ${ }^{11}$, Jens Volkmann ${ }^{11}$, Peter U. Heuschmann ${ }^{1,12,13}$ and Felix Fluri ${ }^{11}$

\begin{abstract}
Background: Telemedicine improves the quality of acute stroke care in rural regions with limited access to specialized stroke care. We report the first 2 years' experience of implementing a comprehensive telemedical stroke network comprising all levels of stroke care in a defined region.

Methods: The TRANSIT-Stroke network covers a mainly rural region in north-western Bavaria (Germany). All hospitals providing acute stroke care in this region participate in TRANSIT-Stroke, including four hospitals with a supra-regional certified stroke unit (SU) care (level III), three of those providing teleconsultation to two hospitals with a regional certified SU (level II) and five hospitals without specialized SU care (level I). For a two-year-period (01/2015 to 12/2016), data of eight of these hospitals were available; 13 evidence-based quality indicators (Qls) related to processes during hospitalisation were evaluated quarterly and compared according to predefined target values between level-I- and level-I/III-hospitals.
\end{abstract}

Results: Overall, 7881 patients were included (mean age 74.6 years $\pm 12.8 ; 48.4 \%$ female). In level-II/II-hospitals adherence of all Qls to predefined targets was high ab initio. In level--hospitals, three patterns of Ql-development were observed: a) high adherence ab initio (31\%), mainly in secondary stroke prevention; b) improvement over time (44\%), predominantly related to stroke specific diagnosis and in-hospital organization; c) no clear time trends (25\%). Overall, 10 out of 13 Qls reached predefined target values of quality of care at the end of the observation period.

Conclusion: The implementation of the comprehensive TRANSIT-Stroke network resulted in an improvement of quality of care in level---hospitals.

\footnotetext{
* Correspondence: katharina.gabriel@uni-wuerzburg.de

${ }^{1}$ Institute of Clinical Epidemiology and Biometry, University of Würzburg, Josef-Schneider-Straße 2/D7, 97080 Würzburg, Germany

Full list of author information is available at the end of the article
}

(c) The Author(s). 2020 Open Access This article is licensed under a Creative Commons Attribution 4.0 International License, which permits use, sharing, adaptation, distribution and reproduction in any medium or format, as long as you give appropriate credit to the original author(s) and the source, provide a link to the Creative Commons licence, and indicate if changes were made. The images or other third party material in this article are included in the article's Creative Commons licence, unless indicated otherwise in a credit line to the material. If material is not included in the article's Creative Commons licence and your intended use is not permitted by statutory regulation or exceeds the permitted use, you will need to obtain permission directly from the copyright holder. To view a copy of this licence, visit http://creativecommons.org/licenses/by/4.0/. The Creative Commons Public Domain Dedication waiver (http://creativecommons.org/publicdomain/zero/1.0/) applies to the data made available in this article, unless otherwise stated in a credit line to the data. 


\section{Background}

\section{Health care in rural areas}

Access to specialized health care in rural areas is often restricted due to limited availability and long travelling distances [1, 2]. This holds also true for treatment of acute stroke patients where treatment delays are associated with worse outcome [3-5]. Approved treatments for acute stroke include intravenous thrombolysis or mechanical revascularization which may improve stroke symptoms. However, these procedures are only effective within a certain time frame [6-8]. Thus, different efforts have been made to shorten the door-to-needle-time (DTNT) by optimizing in-hospital processes $[9,10]$. To reduce the onset-to-door-time (OTDT), however, educational means among the population are needed as well as changes in the pre-hospital admission processes to the nearest qualified hospital. While the first can increase the awareness for stroke signs and for immediate action in the general public, the implementation of telestroke units can reduce the spatial distance to a facility providing help and, thus, avoid time elapsing senselessly $[11,12]$.

Previous studies from Europe and the United States showed differences between urban and rural regions in terms of stroke incidence as well as management after a cerebrovascular event $[13,14]$ resulting in a higher stroke mortality in rural regions compared to urban areas [15]. In addition, a lower awareness and recognition of stroke symptoms as well as of stroke risk factors can be found in the rural population $[16,17]$. Finally, an insufficient training of paramedics in pre-hospital stroke management and considerable delays in triage of stroke patients as well as diagnostic testing and a lack of experience in intravenous thrombolysis have to be counted among the reasons for urban-rural disparities [18].

\section{Telemedical networks}

In order to address the challenge of minimizing rural/ urban differences and providing appropriate health care independent of population density, telemedicine networks were proposed for providing expert support and for bridging long distances by audio-visual means $[19,20]$. In terms of stroke care this means a 24/7service for non-specialised community hospitals provided by hospitals with expertise in stroke care [21]. In Germany, during the last two decades telemedical networks have been established including academic and community hospitals in sparselypopulated regions [21]. While positive impacts have been demonstrated [22, 23], most reports, however, focus on one specific issue, such as the reliable determination of the NIHSS score [24], a timely access to computer tomography [25] or to intravenous thrombolysis [9, 26-30].

\section{Aims}

On the basis of a telemedical stroke network comprising all hospitals in north-western Bavaria (Germany), we aimed to evaluate the impact of the network structure on stroke care in a mainly rural area. Over the first 2 years, the development of a set of predefined health care quality indicators covering aspects of diagnostics, therapy and stroke outcome was analysed in detail.

\section{Methods}

\section{Study region and structure of the network}

The Transregional Network for Stroke Intervention with Telemedicine (TRANSIT-Stroke) was established in October 2014. It covers an area of about $10,500 \mathrm{~km}^{2}$ in north-western Bavaria, comprising Lower Franconia and two neighbouring districts with a catchment area of 1.5 million inhabitants (census 12/2017). According to the NUTS3 definition of the European Union, two-thirds of the area are classified as 'predominantly rural' [31] with a population density of 97 inhabitant per $\mathrm{km}^{2}$.

The TRANSIT-Stroke Network currently comprises a total of 12 hospitals, comprising three levels of expertise in stroke care (status as at 31.03.2019):

- Level-I-hospitals $(n=6)$ provide an intermediate care unit but have no certified stroke unit. They are able to conduct CT and CT-angiography and, thus, intravenous thrombolysis.

- Level-II-hospitals $(n=2)$ provide a regional stroke unit which is certified by the German Stroke Society (DSG) [32]. These stroke units comprise at least four beds and treat at least 250 stroke patients per year. Beside CT and CT-angiography, neuroradiological services are available during regular workinghours and on call.

- Level-III-hospitals $(n=4)$ provide a supra-regional stroke unit certified according to German Stroke Society (DSG), treating at least 500 stroke patients per year. The stroke unit encompasses at least 6 beds. As stroke centres, they allocate access to all relevant therapeutic and diagnostic facilities as well as services of a neurosurgery and an interventional neuroradiology [33, 34].

With these 12 clinical centres in the network, TRAN SIT-Stroke comprises all hospitals offering stroke care within north-western Bavaria and its surroundings. The involvement of all three levels of stroke care is a unique feature within networks located in Germany. A recently published analysis showed, that level-I-hospitals are situated predominantly at the edge of a 30-min-accessibility of level-III-hospitals [35].

Within the network, there is a two-sided interaction between the levels of care. While three of the stroke 
centres (level III) provide teleconsultations for hospitals of level I and II, the latter can transfer patients requiring specialized care to hospitals of higher levels. In addition, specific training options for personnel in level-I-hospitals are provided by specialized personnel of level-IIIhospitals. These included additional teleconsultations focusing on secondary prevention once a month as well as on on-site visits twice a year. Professional face-to-face training courses took place twice a year, at least, in which stroke specific knowledge was taught, such as surveying the NIHSS. During teleconsultations, guidance for conducting intravenous thrombolysis (IVT; dissolving the drug, preparing infusion, administering IVT) was given in case of need step by step. Regarding transferral to another hospital, decision was made by level-III-experts depending on brain image findings, suspected stroke aetiology, and severity of symptoms.. Beside this vertical exchange, there is also a horizontal integration in respect to a lack of specific treatment facilities (i.e., neurosurgery, interventional neuroradiology or intensive care) in level-II/ III-hospitals.

\section{Data collection}

Data on quality of acute hospital care are collected within the regional stroke register Bavaria, a member of the German Stroke Registers Study Group (ADSR) [36]. For patients with a transient ischaemic attack (TIA) (ICD-10: G45) or an ischaemic, haemorrhagic or undefined stroke (ICD-10: I61, I63, I64) a predefined set of data was recorded. Data collection encompassed information on the index event as well as on diagnostics, treatment and outcome. In addition, information on co-morbidities and risk factors as well as on complications and discharge were documented. Data collection is mandatory since 2013. Information was recorded digitally by members of the staff at each hospital and transferred electronically to the coordinating centre of the Bavarian Permanent Working Party for Quality Assurance in Munich, Germany. Completeness of data collection is checked electronically, but not monitored with regard to content. Every participating hospital contributed data for internal analyses. For the present study, however, we included only those hospitals, which were actively involved in the network and delivered data for the whole study period (i.e., 2015 and 2016). Thus, data of eight hospitals were available for this analysis (three level-I-, two level-II- and three level-IIIhospitals). The number of teleconsultations conducted per hospital was recorded on a monthly basis.

\section{Quality indicators (QI)}

In order to measure quality of stroke care, a set of evidence-based quality indicators (QI) was defined covering different aspects of stroke care in the following domains: diagnostics, treatment and outcome [36].
These indicators were developed by the multidisciplinary quality indicator board of the German Stroke Register Study group within a standardized process comprising a literature review, a standardized consensus procedure, an external evaluation and a pilot study [36]. The set of quality indicator is updated regularly. For the present analysis, the following QIs covering different processes of stroke care were analysed [23] using their target values of 2016 (see also Table 2): Brain imaging (CT or MRI) within $60 \mathrm{~min}$ after admission, vascular imaging (ultrasonography, CT-angiography or MR-angiography) within $48 \mathrm{~h}$ after admission, intravenous thrombolysis in patients aged $18-80$ years with symptom onset within $4 \mathrm{~h}$ and an NIHSS score of $\leq 25$ points, treatment with platelet inhibitor $\leq 48$ $\mathrm{h}$ after onset in patients aged $\geq 18$ years, treatment with platelet inhibitor at discharge in patients aged $\geq 18$ years, atrial fibrillation screening in stroke patients without known AF, dysphagia screening within 2 days after admission, mobilization within 2 days after admission, physiotherapy within 2 days after admission, speech therapy within 2 days after admission, rehabilitation assessment in handicapped stroke patients, antihypertensive drug prescription in hypertensive patients, prescription of statins at discharge, door-to-needle-time, and revascularisation of symptomatic carotid stenosis (definition of each single item is provided in the online supplement (see additional file 1)). Target values indicating good quality of care were defined by the quality indicator board of the German Stroke Register Study group.

\section{Statistical analysis}

Statistical analyses were stratified for levels of hospitals (level-I- vs. level-II/III-hospitals). Data are presented as absolute and relative frequencies as well as mean \pm standard deviation (SD) or - where appropriate - as median and interquartile range (IQR). For each QI the percentage of patients fulfilling it was calculated quarterly and put in relation to the respective predefined threshold. Time trends in performance for quarters of 2 years were investigated with (asymptotic) Cochrane-ArmitageTest. The level of significance was set to alpha $=0.05$. All analyses were performed using SAS 9.4.

\section{Ethics}

The TRANSIT-Stroke network and data acquisition has been approved by the Ethic Committee of the University of Würzburg (54/14) and was registered in the German Registry for Clinical Studies (DRKS: No. 11696). The data presented were collected for the purpose of quality assurance and, thus, the identity of the individual patients were anonymous. Therefore, no specific informed consent on individual level was obtained by the patients. 
Table 1 Description of the study population, total as well as stratified for levels of hospitals

\begin{tabular}{|c|c|c|c|c|c|c|c|c|c|}
\hline & & & \multicolumn{2}{|l|}{ total } & \multicolumn{2}{|c|}{ level-I-hospitals } & \multicolumn{2}{|c|}{ level-II/III-hospitals } & \multirow[t]{2}{*}{$p$-value of levels } \\
\hline & & & \multicolumn{2}{|c|}{$n=7881$} & \multicolumn{2}{|c|}{$n=927$} & \multicolumn{2}{|c|}{$n=6954$} & \\
\hline age & & & & & & & & & $<.0001$ \\
\hline years & & mean (SD) & 74.6 & $(12.8)$ & 76.42 & $(12.2)$ & 74.36 & $(12.9)$ & \\
\hline sex & & & & & & & & & 0.0029 \\
\hline male & & $n(\%)$ & 4070 & $(51.6)$ & 436 & $(47.0)$ & 3634 & $(52.3)$ & \\
\hline female & & $n(\%)$ & 3811 & $(48.4)$ & 491 & $(53.0)$ & 3320 & $(47.7)$ & \\
\hline diagnosis & & & & & & & & & $<.0001$ \\
\hline transient ischaemic attack & $\mathrm{TIA}$ & $n(\%)$ & 1938 & $(24.6)$ & 334 & $(36.0)$ & 1604 & $(23.1)$ & \\
\hline ischaemic stroke & IS & $n(\%)$ & 5409 & $(68.6)$ & 527 & $(56.9)$ & 4882 & $(70.2)$ & \\
\hline haemorrhagic stroke & $\mathrm{HS}$ & $n(\%)$ & 504 & $(6.4)$ & 44 & $(4.8)$ & 460 & $(6.6)$ & \\
\hline undefined stroke & US & $n(\%)$ & 30 & $(0.4)$ & 22 & $(2.4)$ & 8 & $(0.1)$ & \\
\hline \multicolumn{10}{|l|}{ treatment } \\
\hline "lyse iv & & $n(\%)$ & 1113 & $(20.6)$ & 50 & $(9.5)$ & 1063 & $(21.8)$ & $<.0001$ \\
\hline \#lyse ia & & $n(\%)$ & 68 & (1.3) & 1 & $(0.2)$ & 67 & (1.4) & 0.0206 \\
\hline \#thrombectomy & & $n(\%)$ & 226 & $(4.2)$ & 2 & $(0.4)$ & 224 & $(4.6)$ & $<.0001$ \\
\hline ventilation & & $n(\%)$ & 378 & $(4.8)$ & 25 & $(2.7)$ & 353 & $(5.1)$ & 0.0014 \\
\hline \multicolumn{10}{|l|}{ diagnostics } \\
\hline dysphagia screening & & $n(\%)$ & 6895 & $(87.5)$ & 396 & $(42.7)$ & 6499 & $(93.5)$ & $<.0001$ \\
\hline long-term ECG & & $n(\%)$ & 7206 & $(91.4)$ & 844 & $(91.1)$ & 6362 & $(91.5)$ & 0.6134 \\
\hline extracranial & & $n(\%)$ & 7457 & $(94.6)$ & 780 & $(84.1)$ & 6677 & $(96.0)$ & $<.0001$ \\
\hline$<48 \mathrm{~h}$ & & $n(\%)$ & 7003 & $(88.9)$ & 583 & $(62.9)$ & 6420 & $(92.3)$ & \\
\hline$>=48 \mathrm{~h}$ & & $n(\%)$ & 454 & (5.8) & 197 & $(21.3)$ & 257 & (3.7) & \\
\hline intracranial & & $n(\%)$ & 7223 & $(91.7)$ & 571 & $(61.6)$ & 6652 & $(95.7)$ & $<.0001$ \\
\hline$<48 \mathrm{~h}$ & & $n(\%)$ & 6939 & $(88.1)$ & 548 & $(59.1)$ & 6391 & $(91.9)$ & \\
\hline$>=48 \mathrm{~h}$ & & $n(\%)$ & 284 & (3.6) & 23 & $(2.5)$ & 261 & (3.8) & \\
\hline \multirow[t]{2}{*}{ NIHSS - at admission } & & & & & & & & & 0.0290 \\
\hline & & median (IQR) & 3 & $(1-7)$ & 3 & $(1-6)$ & 3 & $(1-7)$ & \\
\hline 0 & & $n(\%)$ & 1343 & $(17.1)$ & 168 & $(18.1)$ & 1175 & $(16.9)$ & \\
\hline $1-4$ & & $n(\%)$ & 3643 & $(46.2)$ & 406 & $(43.8)$ & 3237 & $(46.6)$ & \\
\hline $5-15$ & & $n(\%)$ & 2227 & $(28.3)$ & 289 & $(31.2)$ & 1938 & $(27.89)$ & \\
\hline $16-20$ & & $n(\%)$ & 371 & $(4.7)$ & 29 & (3.1) & 342 & $(4.9)$ & \\
\hline $21-42$ & & $n(\%)$ & 294 & (3.7) & 35 & (3.8) & 259 & (3.7) & \\
\hline \multicolumn{10}{|l|}{ mRS - at admission } \\
\hline & & median (IQR) & 3 & $(1-4)$ & 3 & $(1-4)$ & 3 & $(1-4)$ & \\
\hline $0-1$ & & $n(\%)$ & 2191 & $(27.8)$ & 267 & $(28.8)$ & 1924 & $(27.7)$ & 0.4751 \\
\hline $2-6$ & & $n(\%)$ & 5686 & $(72.2)$ & 660 & $(71.2)$ & 5026 & $(72.3)$ & \\
\hline $0-2$ & & $n(\%)$ & 3809 & $(48.4)$ & 454 & $(49.0)$ & 3355 & $(48.3)$ & 0.6880 \\
\hline $3-6$ & & $n(\%)$ & 4068 & $(51.6)$ & 473 & $(51.0)$ & 3595 & $(51.7)$ & \\
\hline \multicolumn{10}{|l|}{$\mathrm{mRS}$ - at discharge } \\
\hline & & median (IQR) & 2 & $(0-3)$ & 2 & $(0-3)$ & 2 & $(0-3)$ & \\
\hline $0-1$ & & $n(\%)$ & 3616 & $(45.9)$ & 453 & $(48.9)$ & 3163 & $(45.5)$ & 0.0550 \\
\hline $2-6$ & & $n(\%)$ & 4259 & $(54.0)$ & 474 & (51.1) & 3785 & $(54.5)$ & \\
\hline $0-2$ & & $n(\%)$ & 5170 & $(65.7)$ & 670 & (72.3) & 4500 & $(64.8)$ & $<.0001$ \\
\hline $3-6$ & & $n(\%)$ & 2705 & $(34.4)$ & 257 & $(27.7)$ & 2448 & $(35.2)$ & \\
\hline
\end{tabular}


Table 1 Description of the study population, total as well as stratified for levels of hospitals (Continued)

\begin{tabular}{|c|c|c|c|c|c|c|c|c|}
\hline \multirow{2}{*}{ Barthel Index - at admission } & & \multirow{2}{*}{\multicolumn{2}{|c|}{$\frac{\text { total }}{n=7881}$}} & \multirow{2}{*}{\multicolumn{2}{|c|}{$\frac{\text { level-I-hospitals }}{n=927}$}} & \multirow{2}{*}{\multicolumn{2}{|c|}{$\frac{\text { level-II/III-hospitals }}{n=6954}$}} & \multirow[t]{2}{*}{$p$-value of levels } \\
\hline & & & & & & & & \\
\hline & mean (SD) & 62.50 & $(35.1)$ & 60.81 & $(34.3)$ & 62.72 & $(35.2)$ & \\
\hline & median (IQR) & 75.00 & $(37.5-100)$ & 52.50 & $(37.5-100)$ & 75.00 & $(37.5-100)$ & \\
\hline \multirow[t]{3}{*}{ Barthel Index - at discharge } & & & & & & & & $<.0001$ \\
\hline & mean (SD) & 73.28 & $(32.7)$ & 75.07 & $(29.8)$ & 73.05 & $(33.1)$ & \\
\hline & median (IQR) & 87.50 & $(50.5-100)$ & 87.50 & $(62.5-100)$ & 87.50 & $(50-100)$ & \\
\hline \multicolumn{9}{|l|}{ Comorbidities } \\
\hline diabetes & $n(\%)$ & 2038 & $(25.9)$ & 255 & $(27.5)$ & 1783 & $(25.6)$ & 0.2243 \\
\hline hyper tonus & $n(\%)$ & 6798 & $(86.3)$ & 805 & $(86.8)$ & 5993 & $(86.2)$ & 0.5983 \\
\hline atrial fibrillation & $n(\%)$ & 2301 & $(29.2)$ & 263 & $(28.4)$ & 2038 & $(29.3)$ & 0.8371 \\
\hline previous stroke & $n(\%)$ & 2269 & $(28.8)$ & 238 & $(25.7)$ & 2031 & $(29.2)$ & 0.0253 \\
\hline onset-to-door-time & & & & & & & & $<.0001$ \\
\hline$<=1 \mathrm{~h}$ & $n(\%)$ & 892 & $(11.3)$ & 63 & $(6.8)$ & 829 & $(11.9)$ & \\
\hline $1-2 \mathrm{~h}$ & $n(\%)$ & 1436 & $(18.2)$ & 144 & $(15.5)$ & 1292 & (18.6) & \\
\hline $2-3 h$ & $n(\%)$ & 780 & (9.9) & 94 & $(10.1)$ & 686 & $(9.9)$ & \\
\hline 3-3.5 h & $n(\%)$ & 257 & (3.3) & 48 & $(5.2)$ & 209 & (3.0) & \\
\hline $3.5-4 \mathrm{~h}$ & $n(\%)$ & 238 & (3.0) & 34 & (3.7) & 204 & $(2.9)$ & \\
\hline $4-6 h$ & $n(\%)$ & 562 & $(7.1)$ & 77 & $(8.3)$ & 485 & (7.0) & \\
\hline $6-24 h$ & $n(\%)$ & 1383 & $(17.6)$ & 189 & $(20.4)$ & 1194 & $(17.2)$ & \\
\hline $24-48 \mathrm{~h}$ & $n(\%)$ & 564 & $(7.12)$ & 85 & $(9.2)$ & 479 & $(6.9)$ & \\
\hline$>48 \mathrm{~h}$ & $n(\%)$ & 812 & $(10.3)$ & 58 & $(6.3)$ & 754 & $(10.9)$ & \\
\hline unknown & $n(\%)$ & 953 & $(12.1)$ & 135 & $(14.6)$ & 818 & $(11.8)$ & \\
\hline \#door-to-needle-time & & & & & & & & $<.0001$ \\
\hline$<=30 \mathrm{~min}$ & $n(\%)$ & 619 & $(11.5)$ & 4 & $(0.8)$ & 615 & $(12.6)$ & \\
\hline $30-60 \mathrm{~min}$ & $n(\%)$ & 409 & (7.6) & 29 & $(5.5)$ & 380 & $(7.8)$ & \\
\hline$>60 \mathrm{~min}$ & $n(\%)$ & 147 & $(2.7)$ & 17 & $(3.2)$ & 130 & $(2.7)$ & \\
\hline no lysis applied & $n(\%)$ & 4232 & $(78.3)$ & 477 & $(90.5)$ & 3755 & $(77.0)$ & \\
\hline length of stay & & & & & & & & 0.1129 \\
\hline days & mean (SD) & 8.5 & $(6.3)$ & 8.8 & $(6.4)$ & 8.4 & $(6.3)$ & \\
\hline \multicolumn{9}{|l|}{ secondary prevention } \\
\hline anticoagulation & $n(\%)$ & 1999 & $(25.4)$ & 244 & $(26.3)$ & 1755 & $(25.2)$ & 0.4836 \\
\hline VitKAnt & $n(\%)$ & 923 & $(11.7)$ & 130 & $(14.0)$ & 793 & $(11.4)$ & \\
\hline NOAK & $n(\%)$ & 1076 & $(13.7)$ & 114 & $(12.3)$ & 962 & $(13.8)$ & \\
\hline statins & $n(\%)$ & 5827 & (73.9) & 763 & $(82.3)$ & 5064 & $(72.8)$ & $<.0001$ \\
\hline IPA within $48 \mathrm{~h}$ & $n(\%)$ & 6053 & (76.8) & 770 & $(83.1)$ & 5283 & $(76.0)$ & $<.0001$ \\
\hline IPA at discharge & $n(\%)$ & 5534 & $(70.2)$ & 673 & (72.6) & 4861 & $(69.9)$ & 0.0281 \\
\hline \multirow[t]{2}{*}{ in-hospital mortality } & & & & & & & & 0.4158 \\
\hline & $n(\%)$ & 423 & $(5.4)$ & 55 & (5.9) & 568 & (5.3) & \\
\hline reason of discharge & & & & & & & & $<.0001$ \\
\hline end of treatment as scheduled & $n(\%)$ & 4938 & $(62.9)$ & 729 & $(78.6)$ & 4209 & $(60.6)$ & \\
\hline end of treatment due to other reason & $n(\%)$ & 123 & (1.6) & 14 & $(1.5)$ & 109 & $(1.6)$ & \\
\hline transfer to other hospital & $n(\%)$ & 477 & $(6.1)$ & 46 & $(5.0)$ & 431 & $(6.2)$ & \\
\hline transfer to acute rehabilitation & $n(\%)$ & 1358 & $(17.2)$ & 68 & $(7.3)$ & 1290 & $(18.6)$ & \\
\hline
\end{tabular}


Table 1 Description of the study population, total as well as stratified for levels of hospitals (Continued)

\begin{tabular}{|c|c|c|c|c|c|c|c|c|}
\hline \multirow[b]{3}{*}{ transfer to skilled nursing facility } & \multirow[b]{3}{*}{$n(\%)$} & \multirow{2}{*}{\multicolumn{2}{|c|}{$\frac{\text { total }}{n=7881}$}} & \multirow{2}{*}{\multicolumn{2}{|c|}{$\begin{array}{l}\text { level-I-hospitals } \\
n=927\end{array}$}} & \multirow{2}{*}{\multicolumn{2}{|c|}{$\frac{\text { level-II/III-hospitals }}{n=6954}$}} & \multirow[t]{3}{*}{$p$-value of levels } \\
\hline & & & & & & & & \\
\hline & & 455 & (5.8) & 13 & $(1.4)$ & 442 & $(6.4)$ & \\
\hline transfer to other department & $n(\%)$ & 107 & $(1.4)$ & 2 & $(0.2)$ & 105 & $(1.5)$ & \\
\hline death & $n(\%)$ & 420 & (5.3) & 55 & (5.9) & 365 & (5.3) & \\
\hline
\end{tabular}

$\#$ as basis only ischaemic stroke is taken, i.e. $5409=527+4882$

\section{Results}

Overall, information on 7881 patients was included in the evaluation, of which 927 (12\%) were treated in level-Ihospitals. Given in total and stratified by hospital level, the distributions in patient characteristics of diagnostics and treatments are displayed in Table 1 . Between 01/2015 and $12 / 2016$, a total of 1896 teleconsultations were conducted in the examined hospitals, whereof 1542 (81\%) have been in interaction with hospitals of level I.

In level-I-hospitals, patients were older and more often female compared to level-II/II-hospitals. In level-Ihospitals, more TIAs but less ischemic strokes were diagnosed compared to level-II/III-hospitals during the whole study period (Table 1).

In level-II/III-hospitals, adherence to QIs was constantly high ab initio (Table 2). Ten QIs out of 15 reported clearly surpassed the target value in every quarter of 2015 and 2016. In five QIs, observed values oscillated closely around the target value.

In level-I-hospitals, observations were more heterogeneous (Table 2). A total of five QIs surpassed the target value ab initio (percentage of patients receiving early mobilisation, atrial fibrillation screening, antihypertensive drugs therapy) (Fig. 1). Their values remained constant over the whole study period. Prescription of inhibitors of platelet aggregation was close to the requested threshold as well, irrespective of whether they were prescribed within $48 \mathrm{~h}$ after onset of stroke or at discharge. QIs showing a high adherence ab initio mainly comprised measures of secondary stroke prevention.

In seven QIs a continuous improvement was observed in level-I-hospitals during the study period. Vascular imaging as well as prescription of statins were raised in level-I-hospitals within the first three quarters of 2015 (trend $p<.0001$ and $\mathrm{p}<.0001$, respectively), surpassing the required threshold and, thereafter, keeping high values (Fig. 2: e, f). Application of physiotherapy was enhanced at an early stage, but then stabilized oscillating around the given threshold (trend $p=0.07$ ) (Fig. 2: d). Implementation of intravenous thrombolysis and transfer to rehabilitation measures proceeded slowly and the required threshold was achieved late (Fig. 2: b, g). In both indices the observed values surpassed the predefined target values only within the last three quarters of 2016. The trend, however, was highly significant (trend $p=0.0015$ and $p=0.0005$, respectively). Screening for dysphagia as well as brain imaging also exhibited a positive trend (trend $p<.0001$ and $p=0.09$, respectively), both items did not reach the required threshold within the study time (Fig. 2: a, c). Indices of quality showing an improvement over time were predominantly related to stroke specific diagnostics and in-hospital organisation.

No clear temporal trend was observed in three QIs in level-I-hospitals (Fig. 3). Values related to the implementation of speech therapy within the first $48 \mathrm{~h}$ oscillated around the threshold value, but did not demonstrate a clear development towards an increased rate (trend $p=0.22$ ). Values regarding the conduction of revascularisation within the first 14 days after onset of stroke as well as the percentage of patients having a door-to-needle-time of less than $60 \mathrm{~min}$ varied tremendously from quarter to quarter. Of note, data of the latter indicators were available for less than $15 \%$ of the total study population. Thus, especially the number of cases reported in level-I-hospitals are very low, i.e. single-digit (results not shown). Indices of quality showing no clear time trends can be grouped as therapeutic measures.

\section{Discussion}

At the end of the first 2 years after establishment of the TRANSIT-Stroke Network in north-western Bavaria, stroke patients received a treatment according to the predefined standards or even better in 10 out of 15 QIs analysed. In level-II/III-hospitals, adherence to target values was constantly high ab initio. In level-I-hospitals, 10 out of 15 QIs surpassed the thresholds of quality of care within the first 2 years after establishing the TRAN SIT-Stroke Network. Thus, stroke care improved in level-I-hospitals since TRANSIT-Stroke was launched.

\section{Population}

Patients assigned to level-I-hospitals were slightly older compared to those assigned to level-II/III-hospitals. This is in line with other studies evaluating urban-rural differences in stroke care [37-39]. However, there are also reports on balanced distribution $[15,18]$ or younger patients in level-I-hospitals $[28,40]$. We observed a higher portion of women in level-I-hospitals while in level-II/III-hospitals the distribution was reversed. This opposite direction of the distribution between the sexes has not been observed 
Table 2 Indicators of quality displayed quarterly, stratified for level of hospital, patients [\%] treated as defined

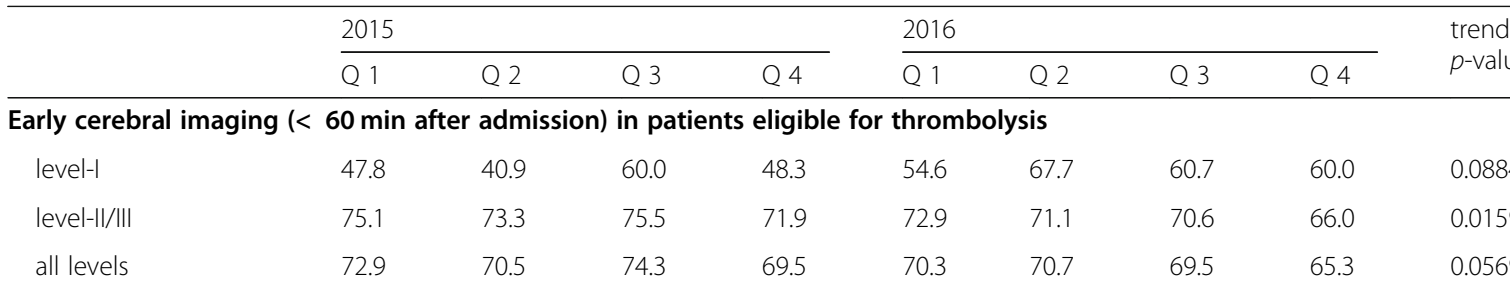

Door-to-needle-time $<60 \mathrm{~min}$ in patients with IVT

\begin{tabular}{|c|c|c|c|c|c|c|c|c|c|}
\hline level-I & 100.0 & 100.0 & 57.1 & 55.6 & 60.0 & 42.9 & 57.1 & 90.9 & 0.6475 \\
\hline level-II/III & 91.8 & 88.6 & 87.3 & 84.7 & 92.3 & 91.0 & 94.8 & 86.2 & 0.8483 \\
\hline all levels & 91.9 & 88.9 & 85.8 & 82.9 & 91.0 & 88.4 & 93.0 & 86.5 & 0.94 \\
\hline
\end{tabular}

Early intravenous thrombolysis (IVT) given in patients with indication for IVT

\begin{tabular}{|c|c|c|c|c|c|c|c|c|c|}
\hline level-I & 0.0 & 10.0 & 8.3 & 20.0 & 13.3 & 35.7 & 28.6 & 44.4 & 0.0015 \\
\hline |evel-II/-III & 40.9 & 43.1 & 47.3 & 39.7 & 40.5 & 45.6 & 45.7 & 41.8 & 0.7612 \\
\hline all levels & 38.9 & 40.8 & 44.3 & 37.9 & 37.5 & 44.8 & 44.1 & 42.1 & 0.4222 \\
\hline
\end{tabular}

Platelet inhibitor given within $48 \mathrm{~h}$ in patients with IS or TIA

\begin{tabular}{|c|c|c|c|c|c|c|c|c|}
\hline level-I & 96.4 & 96.7 & 98.3 & 93.0 & 98.6 & 98.7 & 100.0 & 100.0 \\
\hline level-|I/III & 97.0 & 96.1 & 93.0 & 96.1 & 93.7 & 93.3 & 94.4 & 93.2 \\
\hline all levels & 96.9 & 96.1 & 93.6 & 95.8 & 94.3 & 94.1 & 95.1 & 94.2 \\
\hline
\end{tabular}

\section{Dysphagia screening}

\begin{tabular}{|c|c|c|c|c|c|c|c|c|}
\hline level-I & 26.3 & 33.3 & 56.1 & 35.7 & 32.4 & 55.7 & 58.2 & 59.1 \\
\hline level-II/III & 95.6 & 97.9 & 96.6 & 95.0 & 98.1 & 97.5 & 96.2 & 96.0 \\
\hline all levels & 91.5 & 92.6 & 92.9 & 90.0 & 90.8 & 93.7 & 91.6 & 92.4 \\
\hline
\end{tabular}

Early speech and language therapy for patients with dysphagia / dysphasia / dysarthria

$\begin{array}{llllllllll}\text { level-I } & 63.2 & 58.6 & 85.0 & 65.4 & 61.8 & 97.0 & 72.3 & 73.2 & 0.2191 \\ \text { level-I/III } & 95.9 & 98.2 & 92.0 & 96.0 & 97.6 & 96.3 & 96.3 & 95.2 & 0.9342 \\ \text { all levels } & 94.2 & 94.9 & 91.2 & 93.7 & 93.8 & 96.4 & 93.2 & 92.7 & 0.8144\end{array}$

Early physio- / occupational therapy for patients with motor disability

\begin{tabular}{|c|c|c|c|c|c|c|c|c|}
\hline level-I & 66.7 & 76.9 & 90.3 & 95.2 & 82.1 & 87.5 & 97.5 & 84.2 \\
\hline level-II/III & 97.8 & 97.8 & 97.1 & 98.6 & 97.4 & 98.8 & 96.3 & 97.4 \\
\hline all levels & 96.4 & 95.7 & 96.3 & 98.3 & 96.0 & 97.4 & 96.5 & 95.7 \\
\hline
\end{tabular}

Early mobilisation of patients with severe disability

\begin{tabular}{|c|c|c|c|c|c|c|c|c|}
\hline level-I & 96.7 & 90.7 & 98.1 & 100.0 & 96.2 & 94.6 & 95.9 & 100.0 \\
\hline |evel-|I/III & 97.8 & 98.0 & 95.9 & 97.2 & 97.1 & 98.2 & 95.7 & 94.8 \\
\hline all levels & 97.7 & 97.2 & 96.1 & 97.5 & 97.0 & 97.8 & 95.7 & 95.4 \\
\hline
\end{tabular}

Patients receiving an atrial fibrillation screening during their stay

$\begin{array}{llllllllll}\text { level-I } & 87.5 & 88.4 & 93.3 & 91.4 & 91.0 & 88.3 & 88.3 & 96.3 & 0.2601 \\ \text { level-I/III } & 92.1 & 93.0 & 92.3 & 92.8 & 94.0 & 92.8 & 94.9 & 94.1 & 0.0435 \\ \text { all levels } & 91.8 & 92.4 & 92.5 & 92.6 & 93.6 & 92.2 & 94.0 & 94.4 & 0.0312\end{array}$

Extracranial carotid artery diagnostic in patients with IS or TIA

$\begin{array}{llllllllll}\text { level-I } & 77.4 & 69.2 & 78.6 & 75.5 & 80.0 & 87.9 & 88.1 & 90.8 & <.0001 \\ \text { level-I/III } & 92.4 & 94.9 & 94.1 & 95.8 & 96.7 & 95.7 & 94.5 & 95.0 & 0.0295 \\ \text { all levels } & 91.4 & 92.0 & 92.3 & 93.8 & 94.5 & 94.7 & 93.6 & 94.4 & 0.0006\end{array}$

Revascularisation of symptomatic carotid stenosis in patients with IS or TIA

\begin{tabular}{|c|c|c|c|c|c|c|c|c|c|}
\hline level-I & 0.0 & 100.0 & - & - & 50.0 & 100.0 & 100.0 & 66.7 & 0.4174 \\
\hline level-II/III & 60.0 & 41.2 & 62.5 & 54.2 & 52.6 & 57.1 & 72.7 & 61.5 & 0.3310 \\
\hline
\end{tabular}


Table 2 Indicators of quality displayed quarterly, stratified for level of hospital, patients [\%] treated as defined (Continued)

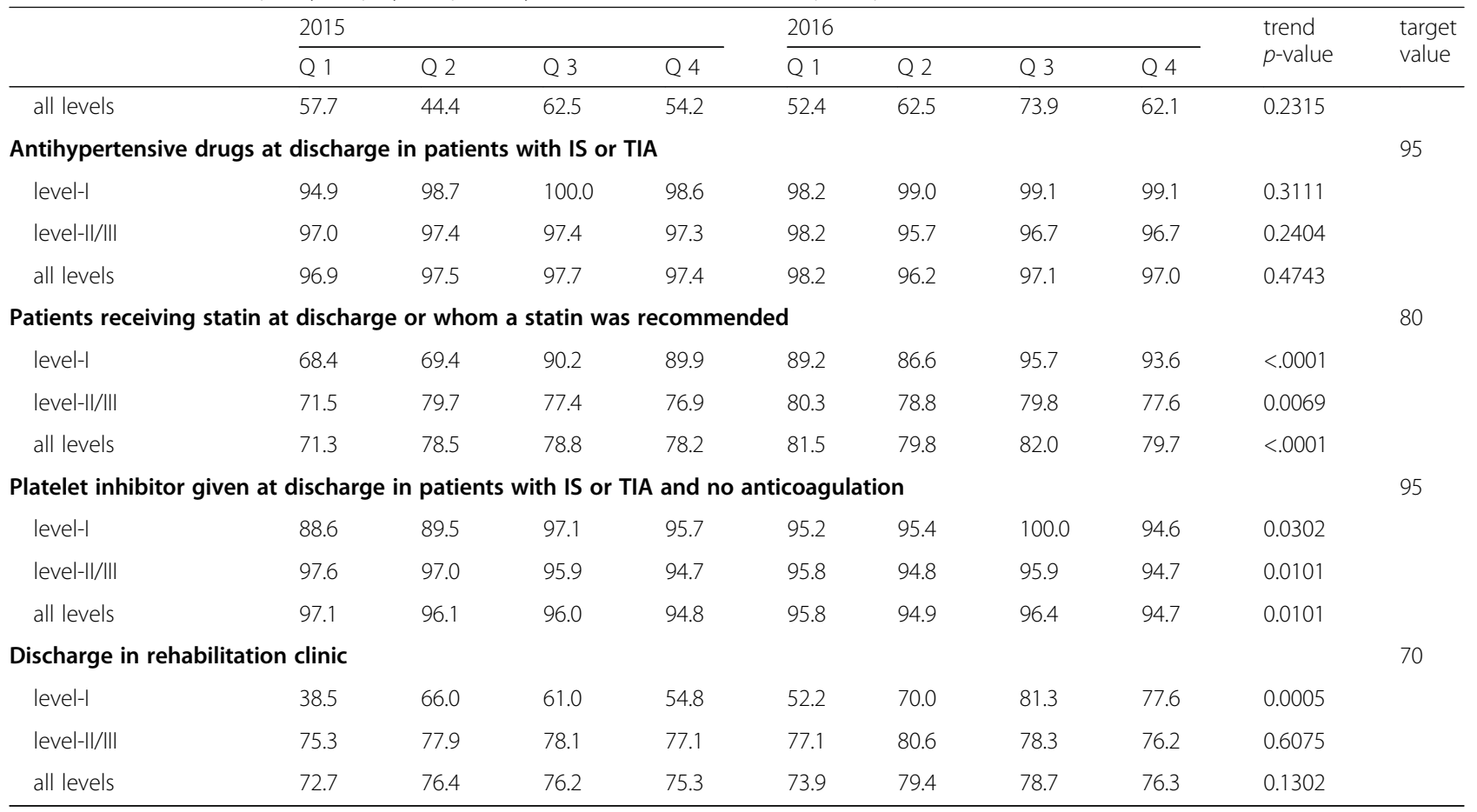

yet. Though other studies also report different proportions of sexes in different hospital levels, the majority clearly stays with one sex $[15,18,28,38,40]$.

While patients with ischaemic or haemorrhagic stroke were transferred to specialized clinical centres, i.e. level-II/ III-hospitals, patients with TIA (ICD-10: G 45) were more frequently treated in level-I-hospitals. The higher proportion of unspecified strokes (ICD-10: I 64) in level-Ihospitals might point out their missing resources to determine the aetiology of stroke. The difference of diagnoses found in stroke centres and in communal hospitals in TRANSIT-Stroke Network was comparable to that in other studies [18, 37]. Of note, this difference appeared irrespectively whether the analysed hospitals were organised in a network [37] or not [18].

In the observed period, a total of 1542 teleconsultations were performed in interaction with level-Ihospitals, of which 927 (60\%) were strokes and TIAs and, thus, 615 (40\%) were mimics or other diseases. This share is consistent with - though much higher than other networks reporting $20 \%$ of mimics [25].

\section{Quality indicators}

\section{Intravenous thrombolysis}

In the first year after implementation, an increase from 0 to $20 \%$ was observed regarding intravenous thrombolysis in eligible patients. The rate of thrombolysis has been more than doubled in the second year of data assessment, achieving a rate of $44 \%$ in level-I-hospitals at the end of the analysed period. This finding was similar to other German telestroke networks [23].

The rate of thrombolysis in the TRANSIT-Stroke Network is not directly comparable to previous studies, as the denominator was restricted to selected patients [21, $23,39]$. Our results support the observation of other telestroke networks, that telemedicine enables comprehensively state-of-the-art treatments [19, 24, 26]. However, diminishing of urban-rural disparities in the use of thrombolysis over time can be observed independently from the established network. In Canada, rural hospitals also extended their medical services regarding thrombolysis and, thus, reduced distance to urban hospitals within a decade [18], without being organised in a network.

\section{Secondary prevention}

Whereas most studies focus on short- and long-term outcomes after thrombolysis recommended via teleconsultation $[22,26,30,41]$, reports on changes in prescribing secondary prevention following teleconsultation are sparse. In TRANSIT-Stroke, prescription of antiplatelet and antihypertension drugs was high ab initio in both, level-I- and level-II/III-hospitals (on average 95 and 98\%, respectively). Studies in Canada and the US [18, 40] corroborate our results regarding antiplatelet drugs but, overall, the percentages of patients receiving antiplatelet therapy was lower (80\%). This was also true for antihypertensive drugs (73\%) [40]. Additionally, the rate in prescribing statins improved in level-I-hospitals significantly with the establishment of TRANSIT-Stroke. 

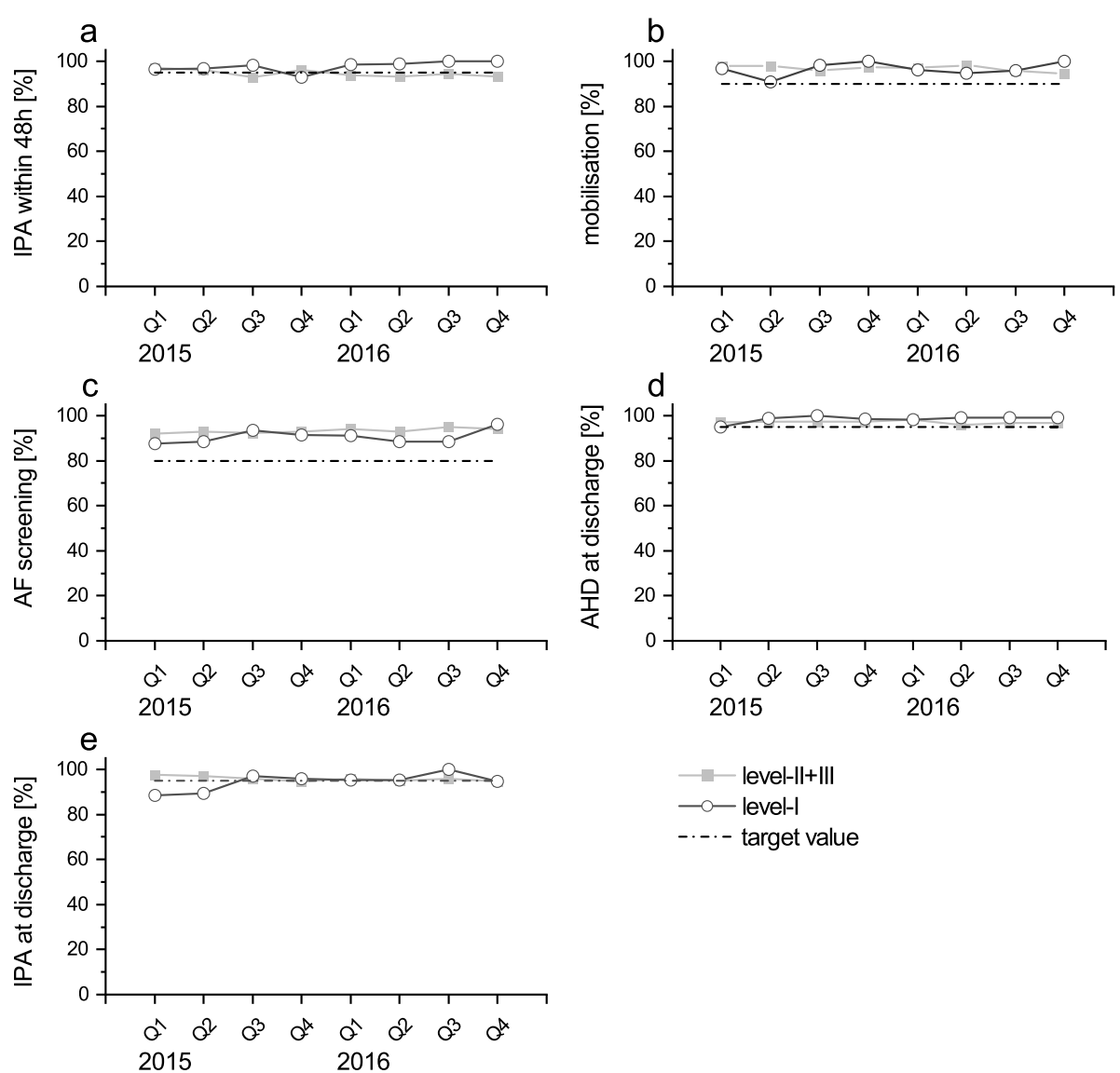

$$
\begin{aligned}
& \longrightarrow \text { level-II+III } \\
& \multimap \circ — \text { level-I } \\
& \ldots-\cdots-\text { target value }
\end{aligned}
$$

2015

Fig. 1 Indicators of quality high ab initio, displayed quarterly, stratified for level of hospital, patients [\%] treated as defined. a) Platelet inhibitor given within $48 \mathrm{~h}$ in patients with IS or TIA. b) Early mobilisation of patients with severe disability. C) Patients receiving an atrial fibrillation screening during their stay. d) Antihypertensive drugs at discharge in patients with IS or TIA. e) Platelet inhibitor given at discharge in patients with IS or TIA and no anticoagulation

Values in the beginning of the study period were comparable to that of rural regions not being part of a network [18, 40]. At the end of the observed period, level-I-hospitals exceeded the predefined treatment targets and even surpassed level-II/IIIhospitals.

\section{Diagnostic examinations after stroke}

Implementation of diagnostic examinations, i.e., brain and vascular imaging as well as dysphagia screening, increased in level-I-hospitals within the first 2 years in the present network. Results for brain imaging reported elsewhere are not comparable since the selected time window from admission to brain imaging was much longer than in the present study ( $1 \mathrm{~h} \mathrm{[21]} \mathrm{and} 24 \mathrm{~h} \mathrm{[38]} \mathrm{vs.} 30 \mathrm{~min})$. However, studies reported a lower number of patients receiving brain imaging in rural areas [38] and have shown that being part of a telestroke network enhanced its utilisation [21]. In respect to carotid imaging, our results exceeded those reported for rural areas in Canada [18] and corresponded with those found in other networks in Germany [21]. Dysphagia screening was performed in $26 \%$ of all patients in level-I-hospitals and, thus, exceeded observations made in rural areas in the US (17\% [39]) ab initio. However, development within 2 years after implementing TRANSIT-Stroke has neither reached the predefined target values nor values observed in another German telestroke network [21].

\section{Rehabilitative measures}

Reports on disparities in rehabilitative measures are sparse in literature. Our findings in level-I-hospitals regarding physiotherapy, speech therapy, occupational therapy and inpatient rehabilitation after discharge exceed those of rural and even of urban areas in the US [18] and were comparable to those in another German telestroke network [21]. 

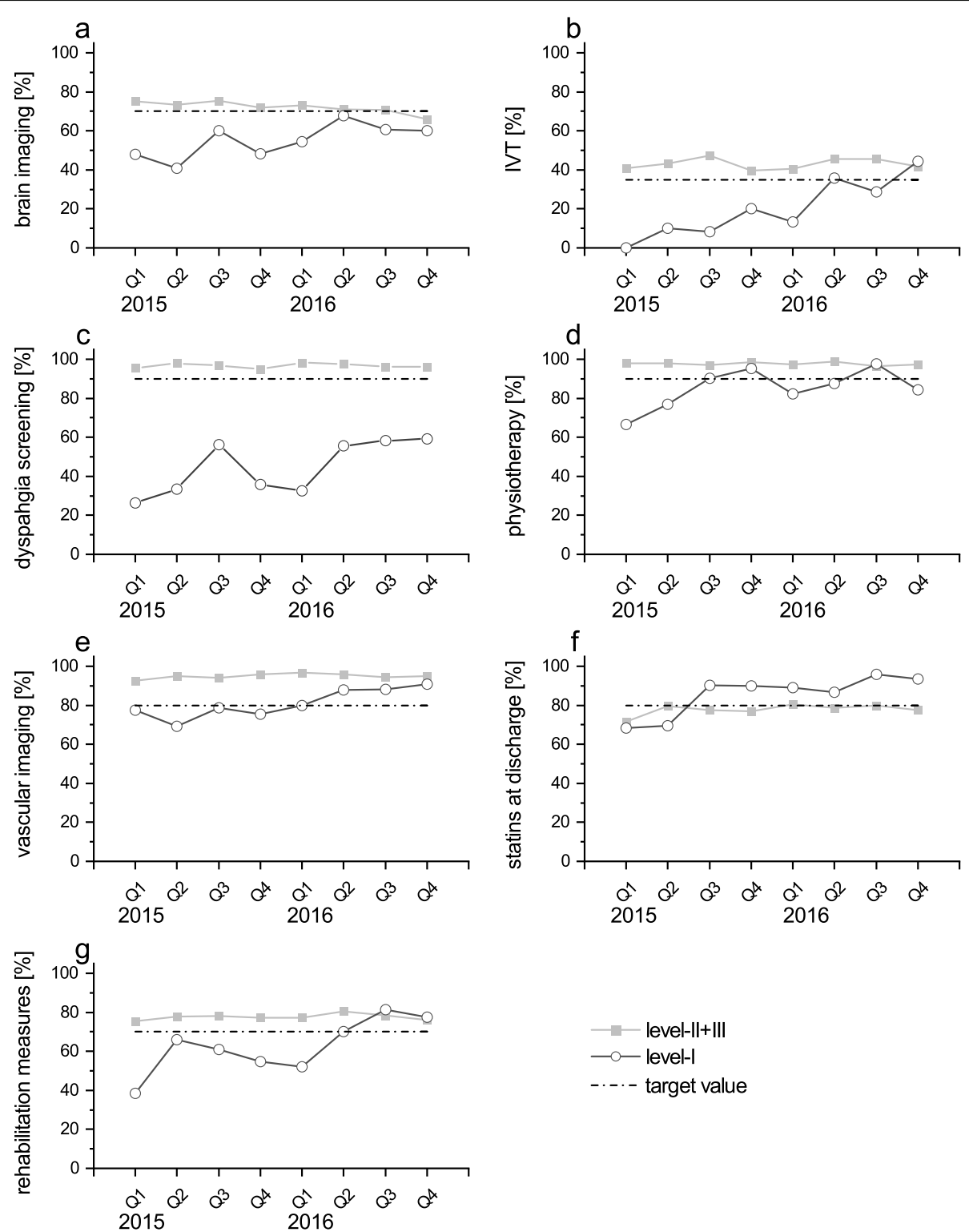

Fig. 2 Indicators of quality increasing over time, displayed quarterly, stratified for level of hospital, patients [\%] treated as defined. a) Early cerebral imaging (<60 min after admission) in patients eligible for thrombolysis. b) Early intravenous thrombolysis (IVT) given in patients with indication for IVT. c) Dysphagia screening. d) Early physio- / occupational therapy for patients with motor disability. e) Extracranial carotid artery diagnostic in patients with IS or TIA. f) Patients receiving statin at discharge or whom a statin was recommended. g) Discharge in rehabilitation clinic

\section{Telemedical networks}

While other networks have hubs and spoke, i.e. two levels of hospitals [23, 41, 42], TRANSIT-Stroke involves all three levels currently defined in Germany. Thereby, all these hospitals are integrated in the network and, thus, in telemedical counselling and in regular training courses. Especially these regular training options within TRANSIT-Stroke are thought to be the reason for the improvement of several QIs in level-I-hospitals.

\section{Strengths and limitations}

The present study has several strengths: The QIs presented in this analysis cover all sections of in-house treatment and describe stroke care extensively. By including different QIs regarding diagnostics, secondary prevention and cerebrovascular imaging, we were able to increase knowledge about issues which have not been investigated well so far; some QIs were even reported for the first time. We are aware of the following limitations: Our results may be biased due to the limited numbers of patients admitted to level-I-hospitals, representing $12 \%$ of the population included in the analysis. This distribution is due to the setting of rather low population density and comparable to other studies investigating urban and rural health care (range from 7 to $16 \%$ ) [14, 18, 39, 40, 43]. In addition, not all 

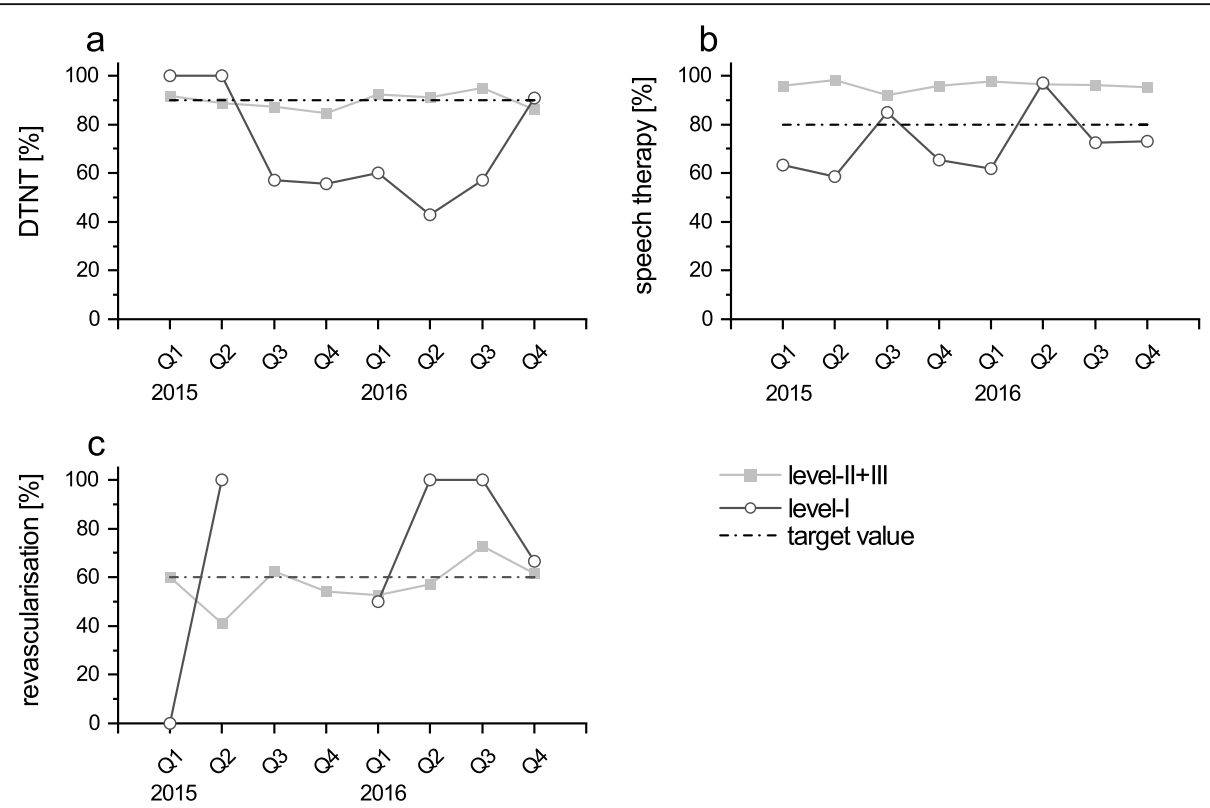

-.-.- target value

Fig. 3 Indicators of quality with no clear temporal trend, displayed quarterly, stratified for level of hospital, patients [\%] treated as defined. a) Door-to-needle-time < 60 min in patients with IVT. b) Early speech and language therapy for patients with dysphagia / dysphasia / dysarthria. c) Revascularisation of symptomatic carotid stenosis in patients with IS or TIA

hospitals participating in the network to date were included in the present analysis. Due to reasons of privacy protection in Germany, transferral within the TRANSIT-Stroke Network could not be considered for analyses. The QIs used in this analysis focused on in-house aspects of stroke care. Thus, issues such as awareness of stroke in the population, reduction of onset-to-door-time before and after implementation of the network or quality of stroke rehabilitation stay disregarded. Assessment of treatment safety, e.g., regular monitoring of haemorrhagic complications (asymptomatic/symptomatic intracranial haemorrhages) was not part of this analysis. However, newly defined quality indicators will be included in further studies to improve additionally health care and, thus, for example, will also consider mechanical thrombectomy. Implausibilities at first sight in the descriptive data, such as reported thrombectomies in level-I-hospitals, were not monitored but can be explained by re-transfer after surgery.

With the implementation of the TRANSIT-Stroke Network the range of specialists' expertise is extended beyond the 30-min-accessibility of level-II- and level-IIIhospitals. Thereby, it is delivered towards rural areas without time delay caused by transportation.

\section{Conclusion}

In conclusion, the implementation of a comprehensive telestroke network in north-western Bavaria raised the quality of care in level-I-hospitals and resulted in an improvement of early stroke-specific diagnostics, inpatient rehabilitative measures and an improvement of secondary prevention.

\section{Supplementary information}

Supplementary information accompanies this paper at https://doi.org/10. 1186/s12883-020-01676-6.

Additional file 1. Brief description of quality indicators applied in this analysis. Definitions of the German quality indicators in acute stroke care as defined by the Quality Indicator Board of the German Stroke Registers Study Group.

\section{Abbreviations}

ADSR: Arbeitsgemeinschaft Deutschsprachiger Schlaganfall-Register (German Stroke Registers Study Group); BAQ: Bayerische Arbeitsgemeinschaft für Qualitätssicherung (Bavarian Permanent Working Party for Quality Assurance); CT: Computer tomography; DRKS: Deutsches Register Klinischer Studien (German Registry for Clinical Studies); DSG: Deutsche SchlaganfallGesellschaft (German Stroke Society); DTNT: Door-to-needle-time;

HS: Haemorrhagic stroke; ICD-10: International Statistical Classification of Diseases and Related Health Problems, $10^{\text {th }}$ Revision; IQR: Interquartile range; IS: Ischaemic stroke; MRI: Magnetic resonance imaging; NIHSS: National Institute of Health Stroke Scale; NUTS 3: Nomenclature of Territorial Units for Statistics, district level; OTDT: Onset-to-door-time; QI: Quality Indicator;

SD: Standard deviation; SU: Stroke Unit; TIA: Transient ischaemic attack; TRAN SIT: Transregional Network for Stroke Intervention with Telemedicine; US: Undefined stroke

\section{Acknowledgements}

An abstract of this work has been presented as a poster [AS12-038] at $4^{\text {th }}$ European Stroke Organisation Conference (ESOC) 2018, held in Gothenburg, Sweden.

\section{Authors' contributions}

Study concept and design: KMAG, SJH, KGH, JV, PUH, FF. Acquisition of data: KMAG, SJH, PK, JM, KD, MK, HS, AR RS, MP, RH, MB, TG, DK, SD, PUH, FF. Statistical analysis: KMAG, SJH, US, VR, PUH. Drafting of the manuscript: KMAG, KGH, PUH, FF. Critical revision of the manuscript for important intellectual content: KMAG, SJH, PK, US, VR, JM, KD, MK, HS, AR, RS, MP, RH, JS, MB, TG, SD, DK, KGH, JV, PUH, FF. Study supervision: KMAG, PUH, FF. The author(s) read and approved the final manuscript. 


\section{Funding}

Organisation and operation of the TRANSIT-Stroke Network as well as the accompanying study is funded by the Bavarian State Ministry of Health and Care and by the statutory health insurances of Bavaria, Germany.

\section{Availability of data and materials}

The data that support the findings of this study are available from Bavarian Permanent Working Party for Quality Assurance in Munich, Germany [Bayerische Arbeitsgemeinschaft Qualitätssicherung (BAQ)] but restrictions apply to the availability of these data, which were used under license for the current study, and so are not publicly available. Data are, however, available from the authors upon reasonable request and with permission of Bavarian Permanent Working Party for Quality Assurance in Munich, Germany [Bayerische Arbeitsgemeinschaft Qualitätssicherung (BAQ)].

\section{Ethics approval and consent to participate}

The TRANSIT-Stroke Network and data acquisition has been approved by the Ethic Committee of the University of Würzburg (54/14) and was registered in the German Registry for Clinical Studies (DRKS: No. 11696). Hospitals signed a legal contract to regulate their interactions within the network. For patients, treatment in the network was independent of informed consent. The data presented were collected for the purpose of quality assurance and, thus, the identity of the individual patients were anonymous. Therefore, no specific informed consent on individual level was obtained by the patients.

\section{Consent for publication}

Not applicable.

\section{Competing interests}

$\mathrm{KGH}$ : received lecture honoraria and/or honoraria for consulting from Bayer HealthCare, Biotronik, Bristol-Myers Squibb, Boehringer Ingelheim, Daiichi Sankyo, Edwards Lifesciences, EIP Pharma, Medtronic, W. L. Gore, Pfizer, Sanofi-Aventis and research grants from Bayer HealthCare and Sanofi-Aventis. PUH: reports grants from German Ministry of Research and Education, German Research Foundation, European Union, Charité-Universitätsmedizin Berlin, Berlin Chamber of Physicians, German Parkinson Society, University Hospital Würzburg, Robert Koch Institute, German Heart Foundation, University Göttingen (within FIND-AF randomized, supported by an unrestricted research grant to the University Göttingen from BoehringerIngelheim), University Hospital Heidelberg (within RASUNOA-prime, supported by an unrestricted research grant to the University Hospital Heidelberg from Bayer, BMS, Boehringer-Ingelheim, Daiichi Sankyo), grants from Charité-Universitätsmedizin Berlin (within Mondafis, supported by an unrestricted research grant to the Charité from Bayer), outside the submitted work. All other authors do not declare any competing interest.

\section{Author details}

'Institute of Clinical Epidemiology and Biometry, University of Würzburg, Josef-Schneider-Straße 2/D7, 97080 Würzburg, Germany. ${ }^{2}$ Neurology, Clinical Centre Main-Spessart, Lohr, Germany. ${ }^{3}$ Neurology, Leopoldina Hospital Schweinfurt, Schweinfurt, Germany. ${ }^{4}$ Neurology, Clinical Centre Rhön, Bad Neustadt/Saale, Germany. ${ }^{5}$ Neurology, Clinical Centre Aschaffenburg-Alzenau, Aschaffenburg, Germany. ${ }^{6}$ Neurology, Clinical Centre Würzburg Mitte, Standort Juliusspital, Würzburg, Germany. ${ }^{7}$ Cardiology, Clinical Centre Helios Frankenwald, Kronach, Germany. ${ }^{8}$ Internal Medicine, Clinical Centre Main, Ochsenfurt, Germany. ${ }^{9}$ Neurology, Clinical Centre Helios Erlenbach, Erlenbach, Germany. ${ }^{10}$ Internal Medicine, Clinical Centre Capio Franz von Prümmer, Bad Brückenau, Germany. ${ }^{11}$ Neurology, University Hospital Würzburg, Würzburg, Germany. ${ }^{12}$ Clinical Trial Center, University Hospital Würzburg, Würzburg, Germany. ${ }^{13}$ Comprehensive Heart Failure Centre, University of Würzburg, Würzburg, Germany.

\section{Received: 24 October 2019 Accepted: 5 March 2020}

\section{Published online: 19 March 2020}

\section{References}

1. Alanee S, Dynda D, LeVault K, Mueller G, Sadowski D, Wilber A, Jenkins WD, Dynda M. Delivering kidney cancer care in rural central and southern Illinois: a telemedicine approach. Eur J Cancer Care. 2014;23(6):739-44.

2. Smith AC, Bensink M, Armfield N, Stillman J, Caffery L. Telemedicine and rural health care applications. J Postgrad Med. 2005;51(4):286-93.
3. Saver JL. Time is brain - quantified. Stroke. 2006;37(1):263-6.

4. Veltkamp R. Akuttherapie des ischämischen Schlaganfalls. Edited by Kommission Leitlinien der Deutschen Gesellschaft für Neurologie, AWMFRegisternummer; 2012;17:030-046.

5. Ringleb PA, Hamann GF, Röther J, Jansen O, Groden C, Veltkamp R. Akuttherapie des ischämischen Schlaganfalls - Ergänzung 2015. Rekanalisierende Therapie. Edited by Kommission Leitlinien der Deutschen Gesellschaft für Neurologie, AWMF-Registernummer; 2015;27:030-140.

6. Lees KR, Bluhmki E, von Kummer R, Brott TG, Toni D, Grotta JC, Albers GW, Kaste M, Marler JR, Hamilton SA, et al. Time to treatment with intravenous alteplase and outcome in stroke: an updated pooled analysis of ECASS, ATLANTIS, NINDS, and EPITHET trials. Lancet. 2010;375(9727):1695-703.

7. Nogueira RG, Jadhav AP, Haussen DC, Bonafe A, Budzik RF, Bhuva P, Yavagal DR, Ribo M, Cognard C, Hanel RA, et al. Thrombectomy 6 to 24 hours after stroke with a mismatch between deficit and infarct. N Engl J Med. 2018; 378(1):11-21.

8. Saver JL, Goyal M, van der Lugt A, Menon BK, Majoie CBLM, Dippel DW, Campbell BC, Nogueira RG, Demchuk AM, Tomasello A, et al. Time to treatment with endovascular Thrombectomy and outcomes from ischemic stroke: a meta-analysis. JAMA. 2016;316(12):1279-89.

9. Hubert GJ, Meretoja A, Audebert HJ, Tatlisumak T, Zeman F, Boy S, Haberl RL, Kaste M, Müller-Barna P. Stroke thrombolysis in a centralized and a decentralized system (Helsinki and Telemedical project for integrative stroke care network). Stroke. 2016;47(12):2999-3004.

10. Meretoja A, Strbian D, Mustanoja S, Tatlisumak T, Lindsberg PJ, Kaste M. Reducing in-hospital delay to 20 minutes in stroke thrombolysis. Neurology. 2012;79(4):306-13.

11. Scott PA, Temovsky CJ, Lawrence K, Gudaitis E, Lowell MJ. Analysis of Canadian population with potential geographic access to intravenous thrombolysis for acute ischemic stroke. Stroke. 1998;29(11):2304-10.

12. Wechsler LR, Demaerschalk BM, Schwamm LH, Adeoye OM, Audebert HJ, Fanale CV, Hess DC, Majersik JJ, Nystrom KV, Reeves MJ, et al. Telemedicine quality and outcomes in stroke: a scientific statement for Healthcare professionals from the American Heart Association/American Stroke Association. Stroke. 2017;48(1):e3-e25.

13. Leira EC, Hess DC, Torner JC, Adams HP. Rural-urban differences in acute stroke management practices: a modifiable disparity. Arch Neurol. 2008; 65(7):887-91.

14. Sergeev AV. Racial and rural-urban disparities in stroke mortality outside the Stroke Belt. Ethn Dis. 2011;21(3):307-13.

15. Howard G, Kleindorfer DO, Cushman M, Long DL, Jasne A, Judd SE, Higginbotham JC, Howard VJ. Contributors to the excess stroke mortality in rural areas in the United States. Stroke. 2017;48(7):1773-8.

16. Callison RC, Leira EC. Strategies to improve acute stroke care of patients in rural and other geographically dispersed areas. Curr Treat Options Neurol. 2008;10(6):450-4.

17. Burgin WS, Staub L, Chan W, Wein TH, Felberg RA, Grotta JC, Demchuk AM, Hickenbottom SL, Morgenstern LB. Acute stroke care in non-urban emergency departments. Neurology. 2001;57(11):2006-12.

18. Koifman J, Hall R, Li S, Stamplecoski M, Fang J, Saltman AP, Kapral MK. The association between rural residence and stroke care and outcomes. J Neuro Sci. 2016;363:16-20.

19. Craig JJ, McConville JP, Patterson VH, Wootton R. Neurological examination is possible using telemedicine. J Telemed Telecare. 1999;5(3):177-81.

20. Rinde E, Nordrum I, Nymo BJ. Telemedicine in rural Norway. World Health Forum. 1993;14:71-7.

21. Audebert HJ, Schenkel J, Heuschmann PU, Bogdahn U, Haberl RL. Effects of the implementation of a telemedical stroke network: the Telemedic pilot project for integrative stroke care (TEMPiS) in Bavaria, Germany. Lancet Neurol. 2006;5(9):742-8.

22. Audebert HJ, Schultes K, Tietz V, Heuschmann PU, Bogdahn U, Haberl RL. Schenkel J, on behalf of the Telemedical project for integrative stroke care (TEMPiS): Long-term effects of specialized stroke care with telemedicine support in community hospitals. Stroke. 2009;40(3):902-8.

23. Müller-Barna P, Hubert GJ, Boy S, Bogdahn U, Wiedmann S, Heuschmann PU, Audebert HJ. TeleStroke units serving as a model of Care in Rural Areas. 10-year experience of the TeleMedical project for integrative stroke care. Stroke. 2014;45(9):2739-44.

24. Wang S, Lee SB, Pardue C, Ramsingh D, Waller J, Gross H, Nichols FT, Hess DC, Adams RJ. Remote evaluation of acute ischemic stroke. Reliability of National Institutes of Health stroke scale via Telestroke. Stroke. 2003;34(10):e188-91. 
25. Bodechtel U, Puetz V. Why Telestroke networks? Rationale, implementation and results of the stroke eastern Saxony network. J Neural Transm. 2013; 120(1):43-7.

26. Audebert HJ, Kukla C, Clarmann von Claranau S, Kühn J, Vatankhah B, Schenkel J, Ickenstein GW, Haberl RL, Horn M. Telemedicine for safe and extended use of thrombolysis in stroke: the Telemedic pilot project for integrative stroke care (TEMPiS) in Bavaria. Stroke. 2005;36(2):287-91.

27. Nguyen-Huynh MN, Klingman JG, Avins AL, Rao VA, Eaton A, Bhopale S, Kim AC, Morehouse JW, Flint AC, on behlaf of KPNC stroke FORCE team. Novel Telestroke program improves thrombolysis for acute stroke across 21 hospitals of an integrated Healthcare system. Stroke. 2018;49(1):133-9.

28. Pervez MA, Silva G, Masrur S, Betensky RA, Furie KL, Hidalgo R, Lima F, Rosenthal ES, Rost N, Viswanathan A, et al. Remote supervision of IV-tPA for acute ischemic stroke by telemedicine or telephone before transfer to a regional stroke center is feasible and safe. Stroke. 2010;41(1):e18-24.

29. Sanders KA, Patel R, Kiely JM, Gwynn MW, Johnston LH. Improving Telestroke treatment times in an expanding network of hospitals. J Stroke Cerebrovasc Dis. 2016;25(2):288-91.

30. Schwab S, Vatankhah B, Kukla C, Hauchwitz M, Bogdahn U, Fürst A, Audebert HJ, Horn M, on behalf of the TEMPiS group. Long-term outcome after thrombolysis in telemedical stroke care. Neurology. 2007;69(9):898-903.

31. EUROSTAT. Overview of the urban/rural type for each NUTS 3 region; 2013 [https://ec.europa.eu/eurostat/web/rural-development/methodology]. Accessed 18 Sept 2018.

32. Deutsche Schlaganfallgesellschaft (German Stroke Society) [www.dsg-info.de;]. Accessed 25 Feb 2019.

33. Hillmann S, Wiedmann S, Rücker V, Berger K, Nabavi DG, Bruder I, Koennecke H-C, Seidel G, Misselwitz B, Janssen A et al: Stroke unit care in germany: the german stroke registers study group (ADSR). In: BMC Neurology. vol. 17; 2017: 8.

34. Nabavi DG, Ringelstein EB, Faiss J, Kessler C, Röther J, Busse O. Regionale und überregionale Stroke-Units in Deutschland. Nervenarzt. 2012;83(8):1039-52.

35. Rauch S, Rauh J. Verfahren der GIS-Modellierung von Erreichbarkeiten für Schlaganfallversorgungszentren. Raumforsch Raumordn. 2016;74(5):437-50.

36. Heuschmann PU, Biegler MK, Busse O, Elsner S, Grau AJ, Hasenbein U, Hermanek P, Janzen RWC, Kolominsky-Rabas PL, Kraywinkel K, et al. Development and implementation of evidence-based indicators for measuring quality of acute stroke care: the quality Indicator Board of the German Stroke Registers Study Group (ADSR). Stroke. 2006;37(10):2573-51.

37. Audebert HJ, Wimmer MLJ, Hahn R, Schenkel J, Bogdahn U, Horn M, Haberl $\mathrm{RL}$, on behalf of the TEMPiS group. Can telemedicine contribute to fulfill WHO Helsingborg declaration of specialized stroke care? Cerebrovasc Dis. 2005;20(5):362-9.

38. Correia M, Silva MR, Matos I, Magalhaes R, Lopes JC, Ferro JM, Silva MC. Prospective community-based study of stroke in northern Portugal: incidence and case fatality in rural and urban populations. Stroke. 2004; 35(9):2048-53.

39. Phipps MS, Jia H, Chumbler NR, Li X, Castro JG, Myers J, Williams LS, Bravata DM. Rural-urban differences in inpatient quality of care in US veterans with ischemic stroke. J Rural Health. 2014;30(1):1-6.

40. Rodriguez D, Cox M, Zimmer LO, Olson DM, Goldstein LB, Drew L, Peterson ED, Bushnell CD. Similar secondary stroke prevention and medication persistence rates among rural and urban patients. J Rural Health. 2011;27(4):401-8.

41. Hess DC, Wang S, Hamilton W, Lee S, Pardue C, Waller JL, Gross H, Nichols FT, Hall C, Adams RJ. REACH: clinical feasibility of a rural telestroke network. Stroke. 2005;36(9):2018-20.

42. Wiborg A, Widder B, for the TESS study group. Teleneurology to improve stroke Care in Rural Areas: the telemedicine in stroke in Swabia (TESS) project. Stroke. 2003;34(12):2951-6.

43. Gonzales S, Mullen MT, Skolarus L, Thibault DP, Udoeyo U, Willis AW. Progressive rural-urban disparity in acute stroke care. Neurology. 2017:88(5):441-8.

\section{Publisher's Note}

Springer Nature remains neutral with regard to jurisdictional claims in published maps and institutional affiliations.

\section{Ready to submit your research? Choose BMC and benefit from:}

- fast, convenient online submission

- thorough peer review by experienced researchers in your field

- rapid publication on acceptance

- support for research data, including large and complex data types

- gold Open Access which fosters wider collaboration and increased citations

- maximum visibility for your research: over $100 \mathrm{M}$ website views per year

At BMC, research is always in progress.

Learn more biomedcentral.com/submissions 